\title{
A Concept to Increase the Bulk Warm Water Production of Ordinary Direct and Indirect Solar-Thermal Systems in Rural India
}

\author{
D. Norta ${ }^{1,2}$, C. Winkler ${ }^{1}$, Adoni-Team ${ }^{1}$ \\ ${ }^{1}$ Regionalgruppe Aachen, Ingenieure ohne Grenzen e.V.

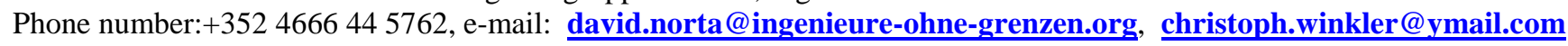

${ }^{2}$ Engineers Without Borders Luxembourg, Campus Kirchberg

6, rue Richard Coudenhove-Kalergi, 1359 Luxembourg (Luxembourg)

Phone number:+352 466644 5762, e-mail: india@ewb-luxembourg.org

\begin{abstract}
This paper focusses on the application of modified solar-thermal water-preheating systems used during the cooking process in large institutions in rural India. The goal is to reduce the fuel consumption. As a second step a concept is presented to promote the solution among wider group of people by providing a webpage to calculate the cost benefit analysis for potential users online. The presented solar thermal system was installed in cooperation with regional partners and "Engineers Without Borders India" in 2012 in Adoni in central Andhra Pradesh after a project site exploration in 2011. The system is still in operation and delivers hot water.
\end{abstract}

\section{Key words}

Solar thermal, efficiency, rural population, fuel wood, natural convection, India, Engineers Without Borders

\section{Introduction}

India is currently a rapidly developing country, seeing a growth rate of above 4 percent of the Gross domestic product within the last years. [1]. The strong development is mainly based on the rapid development in the urbanized areas, the share of the rural population of the GDP is just about $1 / 3$ even though about 2.6 as many people live in the countryside than in the cities [2]. This also leads to a smaller rural availability of well-known renewable technologies due to a concentration of the suppliers on more developed, urbanized regions of the country. Ordinary solar thermal devices here were used in the region of Adoni mostly by larger hotels to provide low cost hot water for hygienic purposes. Due to the lack of a strong economy in the rural areas and therefore a higher share of poor people, social institutions of larger sizes are located there. Those institutions, such as schools, orphanages and social centres offer a shelter to underprivileged people, as the orphanage in which a modified solar thermal system was installed. The often weak financial background of these institutions, mostly operated by religious and other non-profit organizations, as well as the low technological rural standard can lead to inefficient use of daily supplies, especially fuel for cooking purposes. About 80 percent of the rural Indian households rely on firewood as a primary cooking fuel. The same situation was given in the largest institutions visited during the exploration and implementation phase of the project [3]. The average efficiency of the mostcommonly used, simple three-stone-fire is around 15 percent [4]. Therefore a low-cost renewable solution was introduced to preheat water to reduce the fuel consumption of larger institutions.

\section{Motivation}

The considered region of central Andhra Pradesh has a enough annual average solar radiation of about 5.25 $\mathrm{kWh} / \mathrm{m}^{2} /$ day and about 300 sunny days per year [5]. The project site Adoni, is marked by the white point in the first figure.

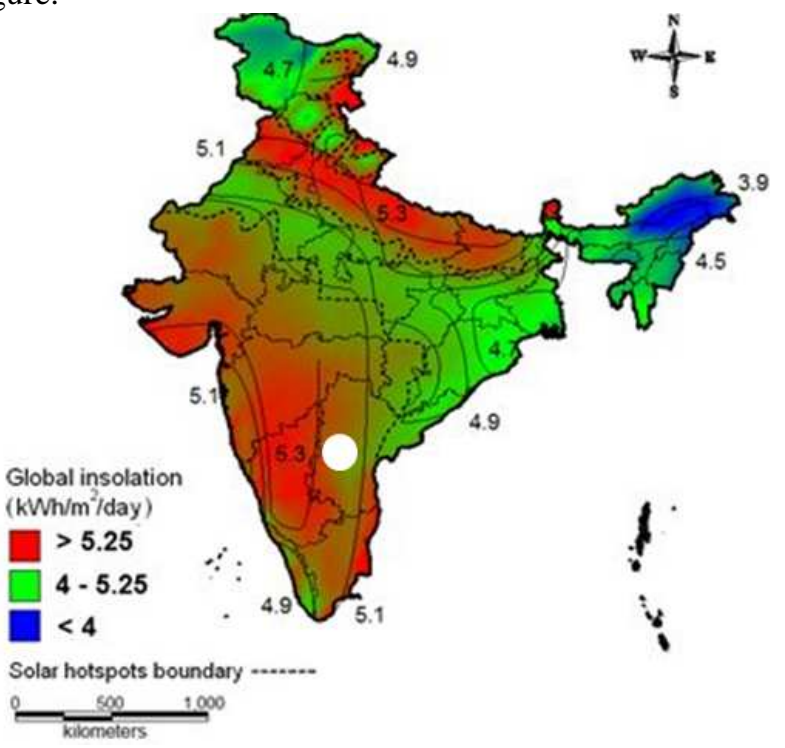

Figure 1. Average annual Irradiation in India [6]. 
Due to the high share of hot water used, during the cooking processes and the good solar irradiance it was decided to use solar thermal devices to preheat the water used in the kitchen. In the following discussion our findings are presented from a four month implementation phase of the presented modified solar thermal system in Southern India and a testing phase about eight month later in 2013. Generally, simple meals were prepared in the visited institutions, dominated by rice combined with differing kinds of sauces, which needed large amounts of hot water during the two to three hours cooking process per meal. The analysis of several cooking processes in different institutions and interviews with the chefs responsible showed that on average about $0,5 \mathrm{~L}$ of hot boiling-hot water per person is used to prepare a simple meal, consisting of the ingredients mentioned above. Ordinary flat plate solar thermal systems have a limited availability of hot water, due to the natural thermo-syphon principle and two layers, of hot and cold water within the storage tank. The ordinary systems' hot-water can be drained from a valve in the upper part of the tank, where the hot layer is located. Every quantity of outflowing hot water is replaced by the same volume of cold-water, filling the tank from a valve at its lowest point. Mixing effects reduce the average water temperature in the tank so that just about half of water in the tank with the initial high temperature can be provided. Due to the exchange of the hot water outflow and the cold water inflow in the proposed setup and an additional installation of a needle valve at the cold water inflow, the cold freshwater-inflow in the storage tank was reduced, while draining the hotwater at the lowest point. Moreover, several systems were installed so that each system serves just one meal. The main motivation behind the project is to reduce the initial investment cost for the system and to increase the amount of hot water provided per modified system, as well as to reduce and partly replace the ordinary fuel consumption (wood, coal, gas, dung).

The application of effective and sustainable technologies, as the proposed solar thermal system, which is widely used and applied in the more developed world, is not really present in the rural parts of India and the mentioned target institutions. Mainly due to a lack of information and motivation of businessmen to develop the rural markets those technologies are not available for the local, rural population. Additionally, the lacking knowledge of current price levels of those technologies and the restricted availability of information about innovative products discourages people of investing in an often cost effective renewable solution, like the proposed system. Therefore, several experiments were made to find out which amount of food and water is used to supply a larger number of people in rural Andhra Pradesh. Current prices of different cooking technologies were analysed. To calculate the economic benefit of a new cooking system compared to the potential customers current cooking solution a calculation tool was implemented and provided on the webpage: www.sustainablecooking.org . Based on this online tool and the communication on regional level between potential target institutions, the system can be promoted and interested people within the less informed, often rural regions can contact supplier to discuss their individual solution.

\section{Methodology}

The project was split into an exploration mission and an implementation mission which lasted one month in 2011 and two and a half months in 2012. During the missions, a detailed solution and available data describing the rainfall and the solar radiation in the region were analysed. No onsite measurements of the irradiation were taken due to the good availability of NASA radiation data for any location on earth and due to the intention of installing a system during the implementation [7]. The elaboration of the contacts to local solar system suppliers in the larger region was one objective of the first part of the project, the closest supplier was found about $340 \mathrm{~km}$ away from the target institution. The individual daily fuel consumption for the preparation of the about 320 meals twice a day was analysed, by conducting interviews with the chefs and measuring the amount of food used per meal as well as the fuel (wood or gas) used for each meal. To validate the measured values at the target location, the way of cooking and the related specific amounts of water and food used, were compared in four different institutions in the region. Simple formulas were deduced to provide an analytical background for the energy consumption estimations in the online tool. Averaged values are used in the cost saving calculator. To dimension the system in the institution mentioned in this publication, mainly the food prepared in the bi-weekly repeating meal plan was analysed and simple time and mass measurements for the different ingredients of each meal were taken. About eight months after the system installation the direct and indirect system were tested and compared between the second and the 14th of August 2013. Different system suppliers were contacted and their prices for different solar thermal systems were compared. The prices differed by their tank size and the number of panels, and did not differ significantly between different suppliers so that in the following the product prices offered by the supplier Nuetech are used. Their products were finally installed onsite. A low efficiency of 40 percent was assumed for the solar thermal system, since no data was available from the supplier [8]. The following plot shows the nearly linear dependence of the solar systems raw price to the tank size. The points in figure 2 are specific system costs from Nuetech for 2012 without VAT and subsidies. No subsidies were considered for the installation of solar thermal systems in the analysis since these are subject to change within the Indian developing energy market and differ between Indian states [8].

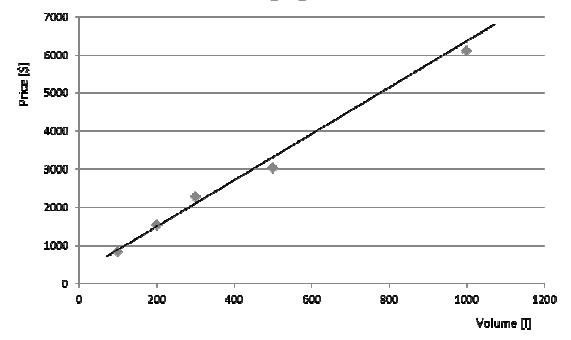

Figure 2. Solar Thermal System prices in India [Nuetech]. 


\section{Results and Analysis}

Three main parts and outcomes of the project can be distinguished. Namely:

1) One system per meal,

2) Exchange water inlet and outlet and to reduce the inflow massively for a constant inflow,

3) Implement online tool to promote the system.

The first finding is that a parallel setup (see figure 3 ) is used to increase the provision of hot water for breakfast and dinner. In the considered institution no lunch was prepared. Compared to a serial setup, each system has a whole day to heat up the water, the only losses per system are the losses during the night for the "breakfast" system, delivering hot water in the morning, which are in the range of 5 to $10^{\circ} \mathrm{C}$ within 12 hours during the night, the values were given by Nuetech. Additional mixing losses within the water tank which will be specified in the next paragraph can be reduced. In a serial setup, see figure 4, the hot water of the first system (1) leaves the first tank for the first meal of the day, the second system (2) will be filled with cold water and push the hot water from tank (2) into tank (1). This process leads to a mixing of the hot and cold water in tank (2). Now the system (1) has just the time from breakfast until dinner to heat up the water about 9 hours during the day (see figure 4).

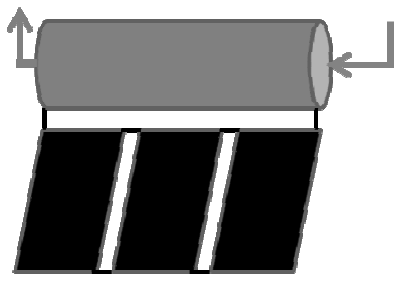

1

Figure 3. Parallel system setup.

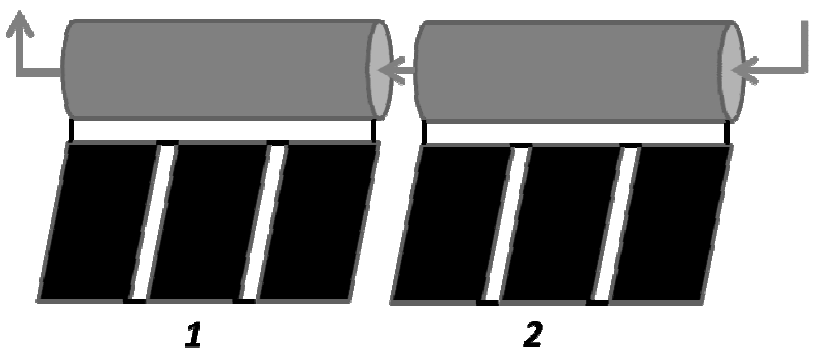

Figure 4. Parallel system setup.

These mixing losses have to be compared with the losses over night in the parallel system. Already a simple comparison of the energy content for a 200 litres system shows that in case of an inflow at $20^{\circ} \mathrm{C}$ and a tank temperature of $100^{\circ} \mathrm{C}$ Celsius and a perfect mixing of 20 litres of the cold and 180 litres of the hot water a temperature drop down to $91.6^{\circ} \mathrm{C}$ Celsius, which exceeds the temperature drop over night of the parallel system of about 5 and meets the 9 degree Celsius (indirect and direct system). The value of 5 and 9 degrees was verified by our on-site measurements from the 7 th to the 8 th of august
2013 for starting temperatures of $48^{\circ} \mathrm{C}$ and $66^{\circ} \mathrm{C}$. Calculating with a tap water temperature of $20^{\circ} \mathrm{C}$ the lost temperature overnight equals a loss of about 35 litre of hot water for the direct and indirect system. Figure 5 shows the energetic mixing efficiency for an increasing amount of cold water $20^{\circ} \mathrm{C}$ mixed with the hot water in the tank $100^{\circ} \mathrm{C}$.

$$
\eta_{\text {mix }}-\frac{\rho_{\text {in }} * V_{\text {in }} * c_{p} * T_{\text {in }}+\rho_{o u t} * V_{o u t} * c_{p} * T_{\text {out }}}{\rho_{100} * V_{\text {Tank }} * c_{p} * T_{100} c}
$$

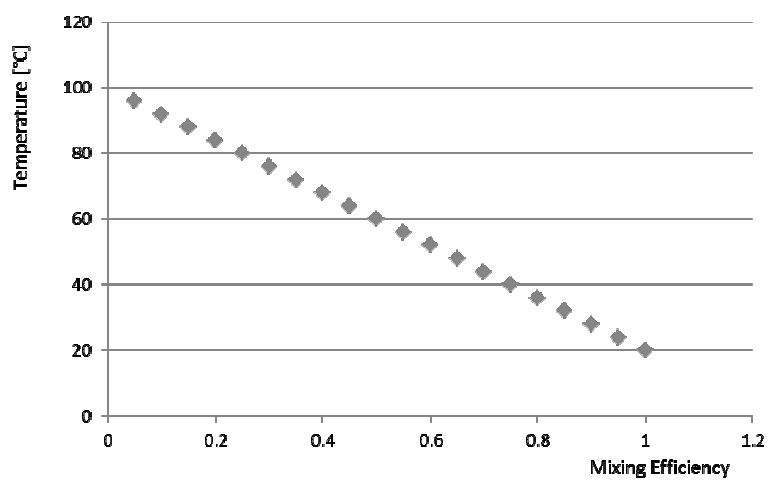

Figure 5. Mixing efficiency, with increasing mass of cold water, the system average temperature decreases.

Figure 6 shows the simplified cross-section with the tank inlets and outlets, the connection of the solar collectors are not shown to simplify the drawing. On the left side of the tank, one can see the outlet of the system. On the right side is the "airvent", which is commonly used in India as a cheap replacement for the pressure exhaust valve, which releases the systems pressure in case of boiling water or any other increased pressure in the tank.

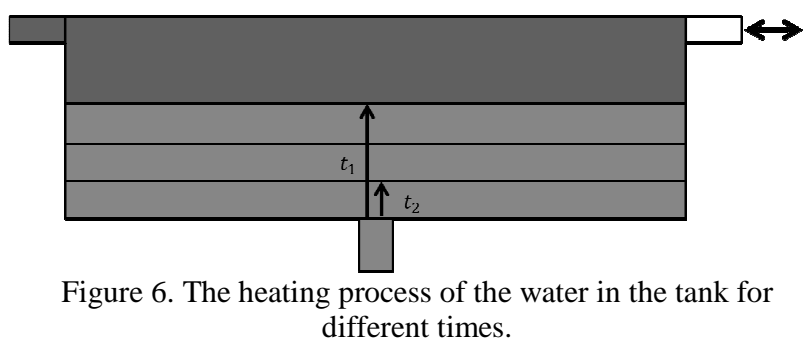

The "airvent" is a permanent connection to the environment, so that the inside tank pressure is equal to the atmospheric pressure. The "airvent" is connected to a pipe which is higher than the maximum height of the water tower connected to the system. Normally those systems in rural India are supplied by a nearby water tower, as on our project site. Due to the natural convection within the solar thermal system the water is propelled through the pipes in the flat plate collectors. Due to the different density, cold water sinks down in the tank and the hot water with its lower density will build a layer in the upper part of the tank (see figure 6). With increasing time and no mass flow of water through the inflow and outflow, the systems' temperature will increase and the layer of cold water will decrease as seen in figure 6 , shown for the cold water layers at $\mathrm{t} 1<\mathrm{t} 2$. 


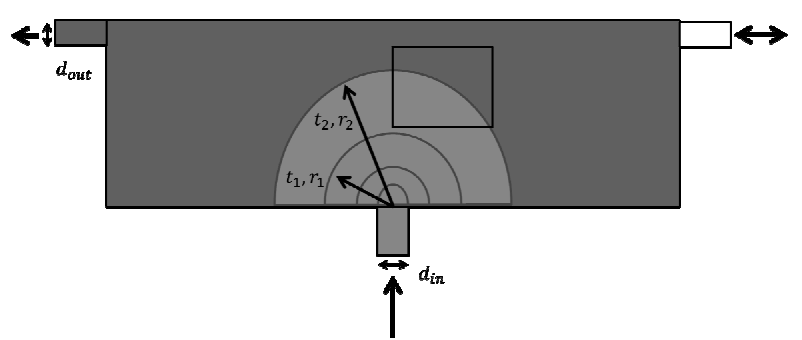

Figure 7. The tank is refilled from the lower inflow valve.

Once the system is emptied, cold water flows into the ordinary system from the lower inlet of the tank in the system, see figure 7 .

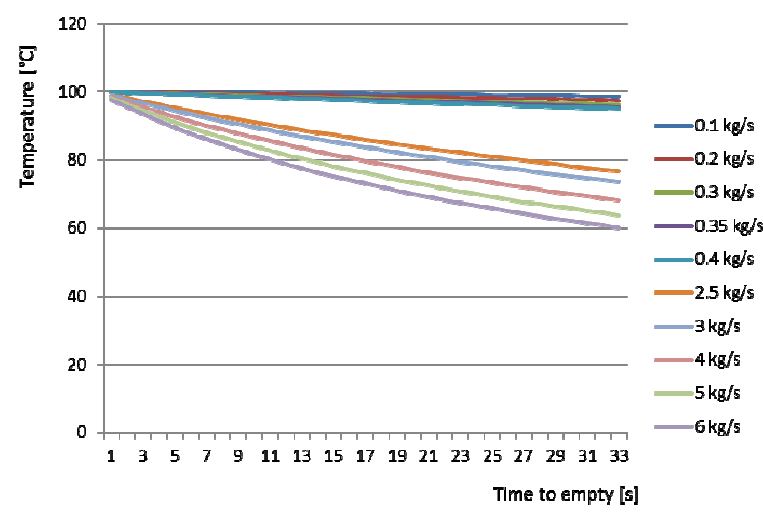

Figure 8 . Decrease of the temperature within the entire system for varying inflows and a steady outflow.

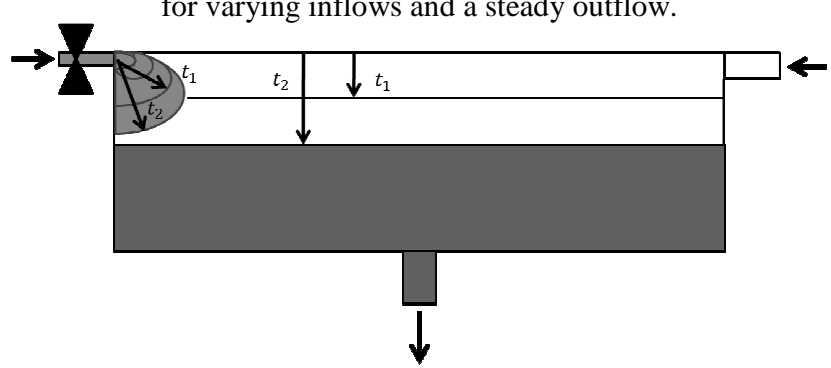

Figure 9. Schematic process of emptying the modified system at the bottom and refill from top.

An exchanged inflow and outflow of the tank is proposed and implemented to increase the provision of more water at a higher temperature, so that the tank can be drained trough the lower valve faster than to refill it through the upper valve, the volume missing between inflow and outflow will be balanced by the air soaked in the tank through the "airvent".

Schematic snapshots of the water level in the tank for the times $\mathrm{t} 1<\mathrm{t} 2$ show the modified system while emptying the tank. The exemplary drawing of the cold water in the upper right corner in blue is shown to understand the mismatch of the inflow and outflow water volume. This effect should be used to reduce the losses within the hot water tank due to mixing effects, in ordinary solar thermal systems due to a reduced cold water inflow. Figure 8 shows how the temperature of the entire system changes, depending on variable cold freshwater mass flows in the tank for a constant outflow rate of $6 \mathrm{~kg} / \mathrm{s}$ (measured in an experiment) which was achieved on site in India.

This plot shows that the theoretical temperature level remains higher, due to the reduced mass flow of cold water in the system. The longer refill timespan of the system, varying from a maximum for the lowest inflow of $0.1 \mathrm{~kg} / \mathrm{s}$ of about $33 \mathrm{~min}$ to a minimum of no refill time for the 200 litres tank, when inflow and outflow are balanced, seems to be a reasonable, considering the reduced capacity of solar harvest during the refill due to a reduced amount of water circulating in the system. Due to the reduced mixing effects and warm water losses the tank size can be smaller than for ordinary systems. Based on the product prices of Nuetech in 2012, a reduced tank size by about the half due to the modification of the system compared to the normally used volume, reduces the initial investment cost on average for the system pairs to 100 litres instead of 200 litres (200/300 300/500 500/1000) by 30 percent.

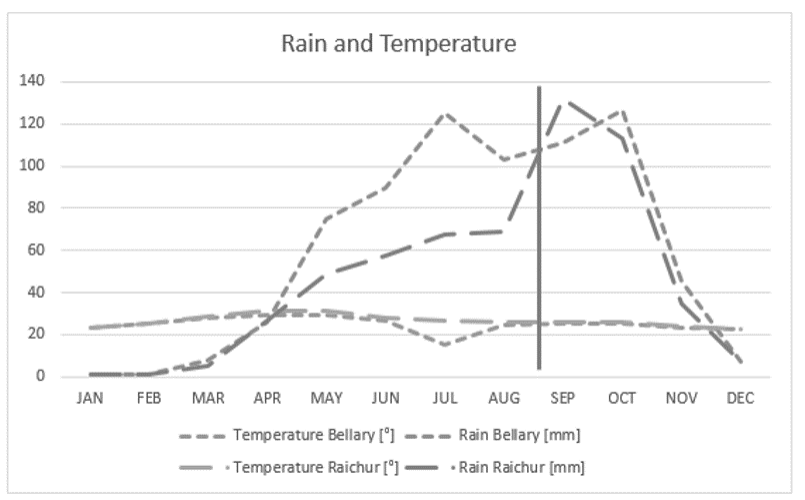

Figure 10. Temperature levels and rain in at two weather stations about $70 \mathrm{~km}$ away from the system location in Adoni (Raichur 73 $\mathrm{km}$ North, Bellary $73 \mathrm{~km}$ South west ).

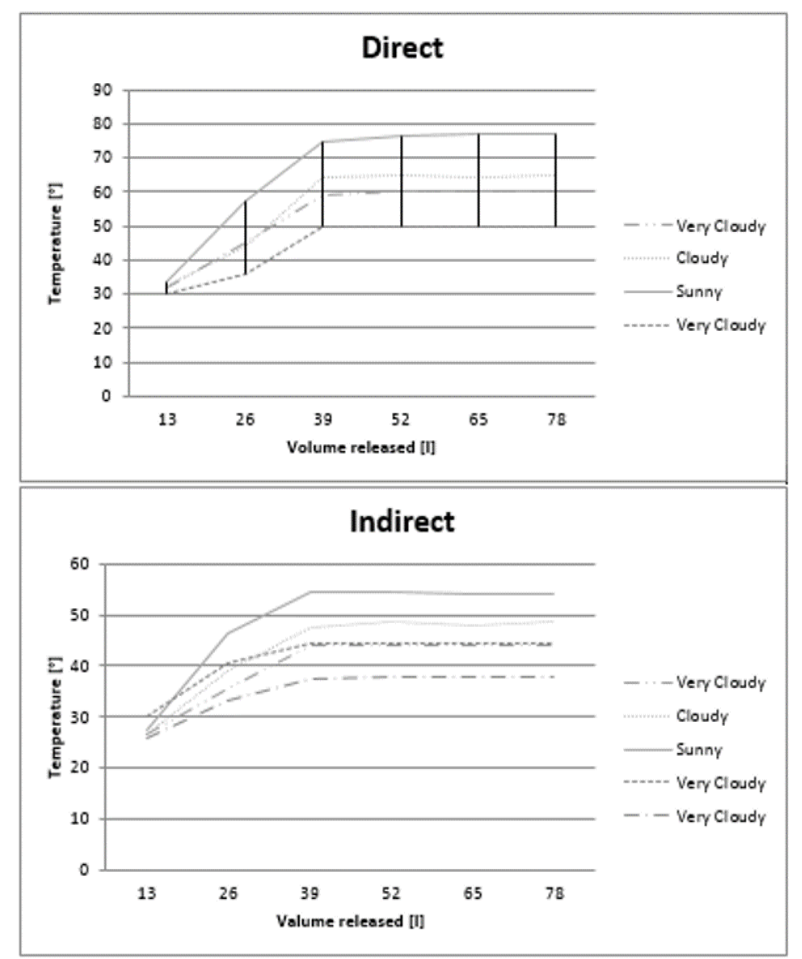

Figure 11. Water temperature while emptying the system for the direct and indirect system at 6.30 PM for different days from the 2nd of August until 6th of August 2013.

Figure 10 shows the average temperature and the average rainfall at the closest climate stations to Adoni, namely in 
Raichur and Bellary, both about $70 \mathrm{~km}$ away from the location. It can be seen that in August a higher amount of rain falls in the region whereas the ambient temperature stays nearly constant. Assuming a higher cloud density and therefore a lower energy harvest of the systems we assume that the systems performance is higher for the rest of the year and the results shown in this publication can be seen as the bottom estimation of energy harvested.

The system serving the institution in Adoni consists of 2 times 200 litres systems with three $2 \mathrm{~m}^{2}$ panels. The performance of the two considered system, direct and indirect system can be observed in figure 11 for different weather conditions. Both systems had one whole day to heat up the water within the tanks, due to limited water resources the tests were interrupted after an extraction 80 litres hot water per system. A direct influence of the weather and especially the cloudiness on the systems end temperature can be seen. As expected the highest temperatures are reached for a sunny day and decrease with the level of cloudiness (three conditions are distinguished sunny/cloudy/heavy clouds). The temperatures vary between 77 and 49 and 54 and 38 degree for the direct and indirect system. This comparison between the energy efficiency of the direct and indirect 200 litres solar thermal system, show that for a direct system higher end temperatures are reached whereas the indirect system has for the same weather conditions a final temperature of about 20 degree less.

The advantage of the indirect system is a lower loss of temperature over night of about 5 degree compared to 9 degree for the direct system, which can be explained by the second fluid cycle which prevents the warm water in the tank from circulating through the panels and cooling down faster. Based on the reduced amount of firewood for each meal, more than 50 percent of the starting amount before the installation, one can say that the system contributes to the institutions energy efficiency. An exact value for the energy saved cannot be given, due to the lack of complete experimental data and the knowledge of the fire woods' energy content, which is the current fuel in those applications. Gas is only used for frying and heating small amounts of water, so that experiments on controllable gas stoves were not possible on the remote project site. A third scientific follow-up evaluation is planned for the end of 2014 to get the missing temperature and volume measurements of the installed systems.

Implementing an online tool, which simply compares potential savings due to preheated water, for different fuels and cooking devices is used to raise awareness for efficient cooking systems in India. The tool is parameterized with prices for fuel for 2012. The tool can be used to compare different cooking fuels and estimates the amount of fuel for a specific Indian meal per person, based on the vast experiments done in India. The system was meanwhile copied and installed in 2013, dimensioned based on the online tool in another institution. The technicians who were involved in the installation of the first system applied without further supervision the new technology, so that the system would reduce the fuel consumption in the second institution. In the following some results of the calculation tool are provided for the institution in Adoni, comparing different solutions and the time until the return of investment. We assumed a price of a gas cylinder of $1279 \mathrm{INR} / 14.2 \mathrm{~kg}$ LPG and a wood price of $3 \mathrm{INR} / \mathrm{kg}$ Wood. The institution prepares six days a week 2 meals for 320 people, consisting of 135 litres of water for the rice and 25 litres of Sauce. Four weeks of holidays per year, when the system is not used, influence the time until the return of investment. An ordinary wood fire needs $22,85 \mathrm{~kg}$ of firewood to prepare the mentioned amount of food. Comparing the cooking process using a solar thermal system and a wood fire with only an ordinary wood fire, the cost saving per year is 9506 INR (3168 kg of wood about $5 \mathrm{~kg} / \mathrm{meal}$ ), for an investment of 30100 INR the return of investment is reached after 3,2 years. This is an increase of cooking efficiency of about 22 percent. Comparing the meal prepared on gas stove the most cost efficient solution is the solar preheated water boiled afterwards on wood fire. A gas stove uses about $3600 \mathrm{~kg}$ of gas per year which costs about 323000 INR for the 613 annual meals. A return of investment is expected after about a month once the customer switched to a wood fire supplied by solar preheated water. In the end of 2012 one \$US was about 52 INR. We did not assume any interest rate in the calculation, because it is expected that the investment will not be financed by a credit and since the interest rates differed a lot in the rural areas. Currently several follow up projects are planned by Engineers Without Borders Luxembourg and Ingenieure ohne Grenzen e.V. regional chapter Aachen.

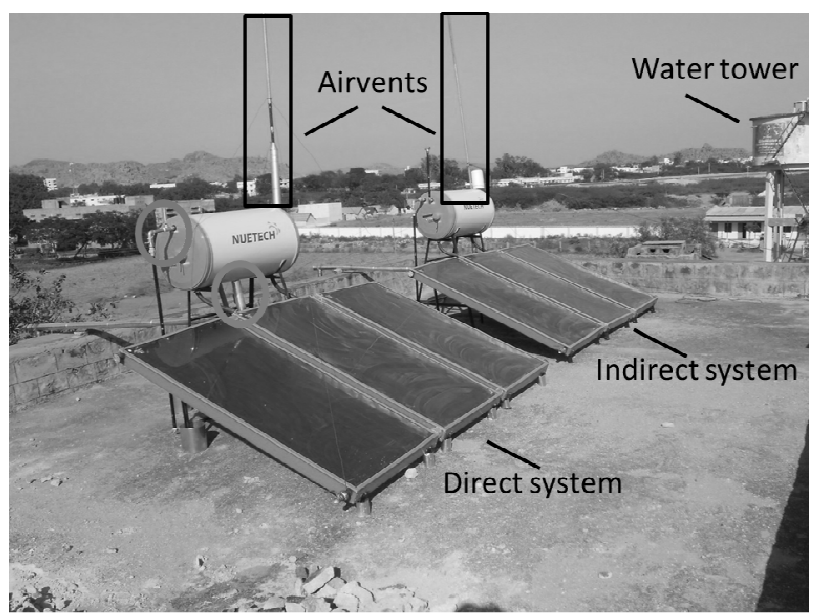

Figure 12. Indirect and direct system, installed on the roof of the institution in Adoni, India. The airvents are indicated. In the background one can see the water tower supplying the systems with freshwater. Circles show hot water outflow (red), cold water inflow.

\section{Conclusion}

A modified solar thermal system is introduced and its ability to preserve a high temperature level during emptying the tank for cooking purposes in large kitchens in social institutions in rural India is shown. A steady temperature level of the warm water for direct and indirect system is reached after an amount of about 40 litre is poured and which is the water content of the pipes between the systems and the roof. Direct systems have a higher end temperature of $77^{\circ} \mathrm{C}$ compared to $54^{\circ} \mathrm{C}$ (direct, indirect), for both systems the end temperature varies in a threshold of about $30 \%$ depending of the weather 
condition. The investment cost in such a modified system can be significantly reduced by 30 percent on average, due to smaller tank size assumed to be enabled by the reversed connection of in- and outflow. Assuming a balanced in and outflow of water in the storage tank, the modified system with a reduced inflow rate of $1 / 60$ of the outflow rate yields to a temperature level which is overall about 40 degrees Celsius higher, based on calculations. In bulk water heating applications as described in this paper, a balanced in- and outflow in an ordinary system leads to a tank size which is at least twice as big as the one of the new system, assuming that the layer of cold water pushes the hot water out of the outflow. The energy loss of hot water in the tank per meal due to the mixing of hot and cold water during the former simultaneous emptying and refilling the tank can be reduced. So the initial investment cost for such a system are reduced by about 30 percent. Compared to the conventional system with a normal wood fire the system saves up to $5.2 \mathrm{~kg}$ of wood per meal for 320 people, where in average $22,85 \mathrm{~kg}$ of wood are burnt without preheated water. Such a solution is cost efficient after 3.2 years. While a solution with preheated water is cost efficient after about a month for a kitchen preparing the food on gas stoves, this is due to the fact of a high LPG price in India of 1279 INR/14.2 kg LPG. More fuel wood or other fuels must be used on extremely cloudy days or during maintenance operations on the system and to keep the temperature of the water on a high level during the cooking of the ingredients. The simple technology currently has a life expectancy of above 25 years. In the four visited institutions two cooked on gas and two on firewood. Proven by the cost calculator based on pure experimental and real market data from 2011/2012 the solar preheated system can be a benefit for larger institutions. The implementation of the a web based tool (www.sustainablecooking.org) as well as the training of local technicians in India, already led to a second installation of the proposed system.

\section{Acknowledgement}

The Adoni project was funded by "Ingenieure ohne Grenzen e.V. Deutschland". In a cooperation with Engineers Without Borders Luxembourg this publication was prepared. A special thank you to the Adoni project team of the Aachen chapter of Ingenieure ohne Grenzen e.V.

\section{References}

[1] India Growth Rate, Trading Economics, 2014 http://www.tradingeconomics.com/india/gdp-growthannual

[2] Rural India shows signs of economic revival but wider outlook glum, Reuters, 2014, http://in.reuters.com/article/2013/11/27/indiaruraleconomy-consumption-agricultuidINDEE9AQ0DZ20131127

[3] Cooking with cleaner fuels in i ndia: a strategic analysis and assessment, Teri, 2010,

http://www.teriin.org/div/CES/Policy_brief_cooking_f uels.pdf

[4] Energy options for cooking in India, N.H.

Ravindranath 1997 ,

http://data2.xjlas.ac.cn:81/UploadFiles/sdz/cnki/\%E5\% A $4 \% 96 \% \mathrm{E} 6 \% 96 \% 87$

[5] Government of Andhra Pradesh, 2012, http://de.slideshare.net/BakulHaria/andhra-pradeshsolar-power-policy-2012

[6] http://wgbis.ces.iisc.ernet.in/energy/paper/hotspot s_solar_potential/results.htm

[7] NASA Surface meteorology and Solar Energy Location, 2014, https://eosweb.larc.nasa.gov/cgibin/sse/grid.cgi?email=skip@larc.nasa.gov

[8] 2014, http://chromasun.com/MCT.html 825 Years of Different Subsidies in India: an Overview, Global Solar Thermal Energy Council 2009, http://solarthermalworld.org/content/25-yearsdifferent-subsidies-india-overview 